\title{
Learning Management System: An Experience and Perception Study from Medical Imaging Lecturers and Scholars in a Private University
}

\author{
https://doi.org/10.3991/ijim.v12i7.9638 \\ Norhayati Mohd Zain( ${ }^{\bowtie}$, Noor Fadzliyana Mohd Fadil, Asma' Abdul Hadi \\ KPJ Healthcare University College, Negeri Sembilan, Malaysia \\ norhayati@kpjuc.edu.my
}

\begin{abstract}
A Learning Management System (LMS) is a virtual interactive medium that modernize the classic classroom interaction in the higher education system. It allows instructors and students to share instructional materials, make class announcements, submit and return course assignments, and communicate with each other online. In KPJ Healthcare University College, Department of Medical Imaging under school of Health Sciences was the first unit that has used LMS actively since 2013. The aim of the study is to determine the perception of Medical Imaging lecturers and scholars on LMS implementation before this system is fully utilized by the university. Using a descriptive study, 200 participants were randomly selected to answer the questionnaire via Google form and 93\% responded. Analysis such as frequencies, percentage and statistical analysis were conducted. The results showed that most of the lecturers and scholars have a positive perception on the system implemented. Implication of the results and future improvement are also presented.
\end{abstract}

Keywords—Learning management system, e-learning, perception, higher education system

\section{Introduction}

The aim of health science curriculum is to provide scholars with adequate knowledge with high competency level in clinical practice to produce best radiographic images for diagnostic purposes; wherever possible and in an evidence-based manner [1]. Traditionally, health science undergraduate education consisted mainly of face-to-face lecturing and the use of paper-based handouts and lecture notes [2]. In evolution of technology mainly the internet, the teaching and learning approaches have been expanded by a new mediation of knowledge via digital e-learning and thereby became part of most interactive method of curricular delivery.

Online learning offers $24 / 7$ availability to more features compared to traditional text books, thus it is very popular among young generations, who love technology which everything is in a single screen [3-4]. E-learning has become common in most universities [5]. Some e-learning set-ups provide uni-directional information for online use or download such as lecture notes and presentations whilst others integrate interactive 
tools like radiographic image evaluation quizzes [3]. Nonetheless, the use of Web 2.0 media with podcasts, wikis or blogs has been implemented for medical teaching [6-7].

Nowadays, the provision of complex blended learning set-ups highly depends on an online platform where scholars and lecturers can get access to them [8]. Different forms of learning management systems (LMS) were established to address the issue. An LMS is the current technology being used as tool for teaching and learning activities [9]. It can be defined as software that automates the administration, tracking and reporting of training events and delivers learning contents rapidly [10].

Department of Medical Imaging (MI) under School of Health Sciences was the first unit in KPJ Healthcare University College that has been using LMS actively since 2013. In conjunction with the upgrading of the university college to a full-fledged university plus improving the implementation of LMS in teaching and learning activities in total, authors feel that it would be helpful if the findings could be documented as institution reference and guideline for the betterment of the university college. Hence, the purpose of this study is to assess the perception of MI lecturers and scholars pertaining to the implementation of LMS.

\section{$2 \quad$ Methodology}

The current cross-sectional descriptive study was conducted in Medical Imaging Department, KPJ Healthcare University College, Kota Seriemas, Nilai, Negeri Sembilan, Malaysia.

\subsection{Participants and sampling technique}

Total sampling technique was used in this study. All MI lecturers $(n=9)$ and all diploma and bachelor MI scholars $(\mathrm{n}=191)$ were recruited in this study. All respondents are familiar with this LMS for at least a year.

\subsection{Data collection}

The questionnaire was constructed and developed into structures and sections. A pilot study was conducted to validate the questionnaire and feedback was gathered. A reliability test was performed by assessing the internal consistency of the items using Cronbach's alpha coefficient test. A value of 0.78 was generated; it is an appropriate reliability coefficient to trust the reliability of the scale for application. Then, the final questionnaire was generated. It includes: Section A: Demographic data and Section B: Respondents' perception on LMS, which comprised of (a) questions on their experiences with LMS, (b) ten items to rank the importance of LMS (5-point Likert response), (c) ten items on their satisfaction on LMS (5-point Likert response), (d) a question on challenges when using LMS, (e) five items on rating their expertise on using the internet (5-point Likert response), (f) overall rating experiences with LMS and the needs of LMS, (g) additionally, students were asked to narratively answer: what they like and dislike about LMS and possible improvement for LMS. 
Participants were either asked to indicate their agreement with each item on a 5 point-Likert scale, with 1 indicating the lowest and 5 indicating the highest. The survey was conducted online via Google form. The online questionnaire was available for 20 days from $4^{\text {th }}$ to $24^{\text {th }}$ October 2017 . We received responses from 191 participants overall ( $93 \%$ response rate). The collected data from questionnaire was analysed by using Statistical Package for Social Science (SPSS) version 21 (IBM Corp, Armonk, New York). Descriptive data were collected, analysed and reported as frequency and percentage in relation to the total numbers.

\section{$3 \quad$ Findings}

From the study, 95\% of the participants were scholars (diploma and bachelor students) and $5 \%$ were lecturers, with a total of $78 \%$ female and $22 \%$ male participants. A total of $80 \%$ of the respondents are in the age range of 18 to 22 years old. Table 1 below shows the participants' answers on 'Are they taught to use LMS?'. Participants recognize that LMS are used in some courses and subjects based on Table 2. A majority of $67 \%$ answered that $1-5$ subjects in a semester were delivered using LMS.

Table 1. Participants' are taught using the LMS

\begin{tabular}{|l|c|c|}
\hline Answers & Frequency & Percent (\%) \\
\hline Yes & 176 & 92 \\
\hline No & 15 & 8 \\
\hline Total & 191 & 100 \\
\hline
\end{tabular}

Table 2. Using LMS for any of the courses or subjects

\begin{tabular}{|l|c|c|}
\hline Answers & Frequency & Percent (\%) \\
\hline Yes & 186 & 97 \\
\hline No & 4 & 2 \\
\hline Missing data & 1 & 1 \\
\hline Total & 191 & 100 \\
\hline
\end{tabular}

LMS is considered as a very important component in the learning process by the participants. In terms of communication tools, web conferencing and academic calendar, $42.4 \%, 47.6 \%$ and $43.5 \%$ admitted these tools are important, respectively. The results revealed that the participants agreed that the LMS tools are very important especially in delivering the subject content (64.4\%), assignment submission (44\%), clinical document submission ( $42 \%)$, online test $(59.7 \%)$, module outcome evaluation $(60.2 \%)$ and timetable tools $(68.1 \%)$. The participants demonstrated positive satisfaction towards all the tools provided in LMS especially on academic calendar (59.7\%) and academic survey $(59.2 \%)$. Some of the tools received high satisfaction, which are assignment submission $(56.5 \%)$ and clinical document submission tools $(56 \%)$. Table 3 revealed the challenges that the participants encountered when using LMS. 
Table 3. Challenges encountered when using LMS

\begin{tabular}{|l|c|c|}
\hline Challenges & Frequency & Percent (\%) \\
\hline I have not had any problems & 63 & 33.0 \\
\hline Difficult to use & 8 & 4.2 \\
\hline Not available when I need it & 26 & 13.6 \\
\hline $\begin{array}{l}\text { Challenges getting it to work on my personal com- } \\
\text { puter }\end{array}$ & 12 & 6.3 \\
\hline $\begin{array}{l}\text { Challenges getting it to work on my personal mobile } \\
\text { phone }\end{array}$ & 36 & 18.8 \\
\hline My instructors do not use it & 6 & 3.1 \\
\hline Not all of my instructors use it effectively & 38 & 19.9 \\
\hline $\begin{array}{l}\text { Access to technology support for technical issues } \\
\text { with the system }\end{array}$ & 29 & 15.2 \\
\hline $\begin{array}{l}\text { Access to my instructor for questions about the } \\
\text { course /assignments }\end{array}$ & 13 & 6.8 \\
\hline Speed is slow when doing online quizzes & 66 & 34.6 \\
\hline Others & 10 & 5.2 \\
\hline
\end{tabular}

The participants were asked on their expertise in the technology items in the following areas: educational activity, research activity, personal activity, entertainment and online shopping. Over half (50.3\%) of those surveyed responded that they are an intermediate user for educational and research activity (53.4\%). While 50.3\% stated that they are expert with the entertainment. This proves that most of the participants have good ICT skills background. A total of $29 \%$ are extremely satisfied with the system, more than half $(58.6 \%)$ of the participants were very satisfied and only $1.1 \%$ was slightly satisfied with the LMS reputation. Table 4 conclude that LMS is very much needed by the participants for their learning process.

Table 4. The need of LMS

\begin{tabular}{|l|c|c|}
\hline Does LMS meet the needs & Frequency & Percent (\%) \\
\hline Fully & 37 & 19.4 \\
\hline Very much & 91 & 47.6 \\
\hline Somewhat & 56 & 29.3 \\
\hline Slightly & 7 & 3.7 \\
\hline Total & 37 & 19.4 \\
\hline
\end{tabular}

To determine the perception of MI lecturers and scholars on LMS implementation, the Bloom's cut-off points of, $81-100 \%$; $60-80 \%$; and $\leq 59 \%$ were adapted and modified from the KAP study [11]. Overall, it shows that $72.3 \%$ of the participants gave a high score but there is still quite high percentage of moderate score $(26.2 \%)$ which will be discussed further in discussion. Finally, the analysis of open-ended survey questions showed that students' responses were mainly positive. 


\section{Discussion}

LMS are defined as a web based technology which assists in the planning, spreading and evaluation of a specific learning process [12]. Meanwhile, Martin [13] defined LMS as software environment designed to manage user learning interventions as well as deliver learning content and resources to students. The key factors for a successful introduction and both effective and persistent usage of digitally supported learning concepts in education in LMS [10]. Hence, this study will determine the MI lecturers and scholars' perceptions on LMS implementation and indirectly recognizing the challenges and limitation faced by them.

LMS offers various kind of tools like communications tools, web conferencing, academic calendar, subject content, assignment submission, clinical document submission, online tests, survey, course syllabus and timetable. Both MI lecturers and scholars admit that online tools was an important resource and useful in online learning environment, especially for assignment submission and clinical document submission where it makes work a lot more easier than the traditional approach. Communication and web conferencing tools get a quite high score of "neither important nor unimportant" with $14.7 \%$ and $18.8 \%$ respectively. These tools are rarely used by participants as there is no urge for them as they still can contact each other directly via phone calls, messages and emails [10].

Based on previous studies, students' satisfaction on LMS is based on either they were taught on how to use the LMS [14], experience in using ICT and training [15]. Thus, based on $92 \%$ of participants who had been taught using LMS, most of them are satisfied with the tools in LMS. Although assignment and clinical document submission tools received a high score of "very important" by $56.5 \%$ and $56 \%$, respectively, there are still challenges complained by the participants. They complained that the submissions of clinical posting documents are not user friendly due to a few technical issues: There are also complains on networking problems and system not updated.

Good internet connection is essential for LMS to work smoothly. Most of the challenges faced by the lecturers and scholars are due to technical problem from slow or unreliable internet connection especially during submission and online tests where many users are online at time creating internet traffic. Suggestion should be made to the university to plug in a high-band width network that can provide a high-capacity online service that is affordable.

ICT skill is also one of the program learning outcomes that is adopted in Faculty of Health Sciences [16]. This study finding also points to show the participants rated as an intermediate to advance user for most of the technology item except for online shopping, which is pleasing to know although they are also expert in entertainment areas which are not surprising. In determining participants' overall satisfaction on LMS, study by Eom [17] stated that, out of the four antecedent constructs hypothesized to affect user satisfaction with LMS, only two which are information quality and readiness for online learning are significant. Both components are cleared in this study.

In terms of perception, most of MI lecturers and scholars accumulate a high score (80-100\%) that indicates positive perception towards LMS. However, it appears that there is $26.2 \%$ of the participants gathered moderate score with a total mark of $60-80 \%$, 
showing neutral perception. A possible explanation is because there are still presence of physical constraints, personal constraints and administrative constraints [18].

\section{Conclusion}

Majority of MI lecturers and scholars have positive perception on LMS. The use of LMS as a medium of teaching and learning may hold the promise of a more studentcentered approaches which are in parallel with what is being instilled by the outcomebased education implemented earlier, one that inspires students to extent across the boundaries of academic terms and learning disciplines. In order to ensure LMS to increase the quality of learning, a suggestion should be made to the university to improve the server and make it more users friendly. Furthermore, the lecturers and scholars need to be equipped with technological skills by attending series of training, and encouraging them to be more interactive.

\section{Acknowledgment}

The authors would like to express their gratitude to who have contributed to this study formally and informally. This study received financial support from KPJ Healthcare University College and follows all ethical practices during writing.

\section{$7 \quad$ References}

[1] Loyola, S. (2010). Evidence-based teaching guidelines: transforming knowledge into practice for better outcomes in healthcare. Crit Care Nurs Q, 33:19-32. https://doi.org/10.1097/ CNQ.0b013e3181c8e309

[2] Shephard, R. J., Ashley, M. J. (1979) Attitudes of health science students towards teaching practices, examinations, and other related issues. Med Educ, 13:111-6. https://doi.org/10.1111/j.1365-2923.1979.tb00932.x

[3] Ridgway, P. F., Sheikh, A., Sweeney, K. J., Evoy, D., McDermott, E. Felle, P., et al.(2007) Surgical e-learning: validation of multimedia web-based lectures. Med Educ, 41:168-72. https://doi.org/10.1111/j.1365-2929.2006.02669.x

[4] Gesundheit, N., Brutlag, P., Youngblood, P., Gunning, W. T., Zary, N., Fors, U. (2009).The use of virtual patients to assess the clinical skills and reasoning of medi-cal students: initial insights on student acceptance. Med Teach, 31:739-42. https://doi.org/10.1080/014215 $\underline{90903126489}$

[5] Back DA, Haberstroh N, Sostmann K, Schmidmaier G, Putzier M, Perka C, Hoff E. (2014). High efficacy and students' satisfaction after voluntary vs mandatory use of an e-learning program in traumatology and orthopedics--a follow-up study. J Surg Educ, 71:353-9. https://doi.org/10.1016/j.jsurg.2013.11.007

[6] Boulos, M. N., Maramba, I., Wheeler, S. (2006) Wikis, blogs and podcasts: a new gen-eration of Web-based tools for virtual collaborative clinical practice and education. BMC Med Educ, 6:41. https://doi.org/10.1186/1472-6920-6-41 
[7] Sandars, J., Homer, M., Pell, G., Croker, T. (2008), Web 2.0 and social software: the medical student way of e-learning. Med Teach, 30:308-12. https://doi.org/10.1080/014215907017 $\underline{98729}$

[8] Gray, K., Tobin, J. (2010). Introducing an online community into a clinical education setting: a pilot study of student and staff engagement and outcomes using blended learning. BMC Med Educ, 10:6. https://doi.org/10.1186/1472-6920-10-6

[9] Hadi, A. A. \& Zain, N. M. (2016), Student's Perception towards Program Outcomes in Faculty of Health Science, KPJ Healthcare University College. International Journal of Education and Research, 4(3): 257-264.

[10] Back, D. A., Behringer, F., Haberstroh, N., Ehlers, J. P., \& Sostmann, K. (2016). Learn-ing management system and e-learning tools : an experience of medical students' us-age and expectations, 267-273. https://doi.org/10.5116/ijme.57a5.f0f5

[11] Mulat Yimer, Bayeh Abera, Wondemagegn Mulu, Belay Bezabih. Knowledge, Attitude and Practices of High Risk Populations on LouseBorne Relapsing Fever in Bahir Dar City, North-West Ethiopia. Science Journal of Public Health. Vol. 2, No. 1, 2014, pp. 15-22. doi: 10.11648/j.sjph.20140201.13 https://doi.org/10.11648/j.sjph.20140201.13

[12] Alias, N.A., \& Zainuddin, A.M. (2005). Innovation for Better Teaching and Learning: Adopting the Learning Management System. Malaysian Online Journal of Instruc-tional Technology, 2, $27-40$.

[13] Martin, F. (2008). Blackboard as the Learning Management System of a computer liter-acy course. Merlot Journal of Online Learning and Teaching. 4(2), 138-145.

[14] Tseng, K. H., Chiang, F. K. \& Hsu, W. H. (2008). Interactive processes and learning attitudes in a web-based problem based learning (pbl) platform. Computers in Human Behaviour, 24(3), 940-955. https://doi.org/10.1016/j.chb.2007.02.023

[15] Mahmud, R., \& Ismail, M. A. H. (2010). Impact of Training and Experience in Using ICT on in-Service Teachers' Basic ICT Literacy. Malaysian Journal of Educational Technology, 10(2), 6.

[16] Zain, N. M., Hamid, K. A., \& Hadi, A. A. (2016). European Journal of Education Stud-ies Outcome Based Education: A Perception from Private Health Sciences. European Journal of Education Studies, 2(6), 78-86. Retrieved From http://Oapub.Org/Edu/Index.Php/ Ejes/Article/View/271/668

[17] Eom, S. B. (2014). Understanding e-Learners' Satisfaction with Learning Management Systems, 16(2), 3-6.

[18] Hussein, H. B. (2011). Attitudes of Saudi Universities Faculty Members towards Us-ing Learning Management System (JUSUR), 10(2), 43-53.

\section{Authors}

Norhayati Mohd Zain is a Medical Imaging Senior educator, Research Coordinator, and Head of Medical Imaging Department. She works also as a Deputy Dean of School of Health Sciences in KPJ Healthcare University College, Malaysia.

Noor Fadzliyana Mohd Fadil is a Medical Imaging educator in Medical Imaging Department, School of Health Sciences; KPJ Healthcare University College, Malaysia.

Asma' Abdul Hadi is a final year scholar in Bachelor in Medical Imaging Program School of Health Sciences; KPJ Healthcare University College, Malaysia.

Article submitted 04 October 2018. Resubmitted 24 October 2018. Final acceptance 07 November 2018. Final version published as submitted by the authors. 